\title{
Organ failure
}

\section{Across continental Europe, historical instruments are falling silent, muted by a new and mysterious form of corrosion. Tom Clarke speaks to the chemical detectives who are striving to protect our musical heritage.}

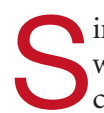
ince 1467, the pure sound of the Stellwagen organ has filled the parish church of St Jakobi's in Lübeck, Germany. Named after the great organ builder Friedrich Stellwagen, who renovated it in the seventeenth century, aficionados rate the Lübeck organ as among the world's best for performing Renaissance and early baroque music. But in 1992, its largest pipes began to lose their voice. Close inspection revealed the problem: air was escaping through tiny holes that had appeared in the metal.

News of the renowned organ's affliction spread quickly among Europe's close-knit community of organ builders, players and enthusiasts. And the word in the organ loft was that Lübeck's Stellwagen was not alone. Pipes in many instruments dating from the fifteenth, sixteenth and seventeenth centuries from churches in Belgium, France, Italy, the Netherlands and Portugal are similarly rotting away - those of the organ in Bordeaux Cathedral are in danger of collapsing under their own weight.

The pipes of ancient organs are made from lead, which is known to corrode. But the symptoms seen in the Lübeck Stellwagen and its fellow sufferers - the sudden appearance of white chalky residue on a pipe's interior that eventually works its way through to the outside — hadn't been encountered previously. "We really think that we're dealing with something new," says Carl Johan Bergsten, a research engineer at the Organ Art Center at Gothenburg University, Sweden. Bergsten views the instruments as both musical and technological icons. "They mirror the technical achievements of their age," he says. "An organ was the seventeenth century equivalent of the PC."

\section{Following the lead}

Last year, Bergsten assembled a team of metallurgists, chemists, organ makers and music historians to establish the cause and extent of the problem. It's early days, but the team's laboratory and field experiments have started to yield clues about the cause of the corrosion - and it seems that it may be a by-product of well-meaning attempts to restore the precious instruments.

Bergsten's Corrosion of Lead and LeadTin Alloys of Organ Pipes in Europe project - funded by the European Union and known by its acronym, COLLAPSE - is inviting organ builders, restorers and organists to send it details of corroded organs. Just last month,

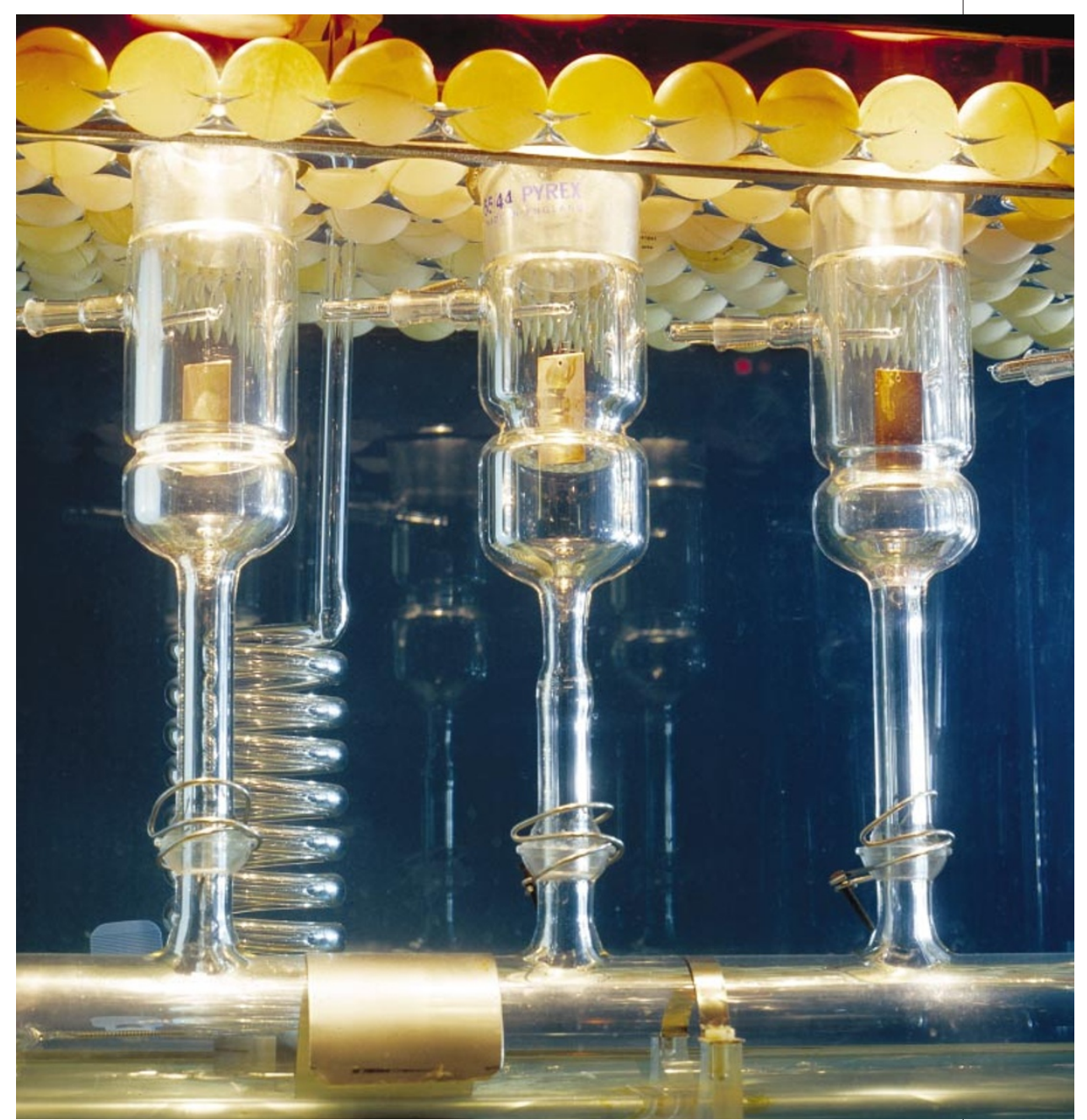

Finely tuned: lead samples from organs are tested for corrosion under various atmospheric conditions.

for example, the Royal Conservatory in Brussels contacted Bergsten after realizing that its organ had fallen victim to lead corrosion.

Understanding the distribution of the problem might help to identify its cause. But the project's main detective thrust is a series of field and lab experiments. Bergsten's team has already selected seven corroded organs in Italy, Germany and the Netherlands and paired them with similar non-afflicted organs in similar churches in the same area. Instruments recording temperature and humidity have been installed in these churches, and samples of corroded and uncorroded metal from their organ pipes have been examined in the lab of Jan-Erik Svensson, an environmental inorganic chemist at the Chalmers University of Technology in Gothenburg.

Organ enthusiasts weren't short of theories about the cause of the corrosion. One leading suspect was central heating. As well as increasing the temperature and humidity, heating systems also release carbon monoxide, which can corrode metals. But Svensson's analysis suggested an alternative cause. "We immediately found high concentrations of organic acids," he explains. The powdery white residue turned out to be lead hydroxycarbonate and lead hydroxyacetate, symptomatic of organic-acid corrosion. Sampling inside the corroded pipes immediately pointed to a culprit: high levels of acetic acid in the air blowing through them. 
